\title{
PROTOTIP EDDY AKIMI AYRIŞTIRICISI İLE BAZI DEMİRSİZ METALLERİN GERİ KAZANIM PERFORMANSININ BELİRLENMESİ
}

\author{
Ahmet FENERCIOĞLU ${ }^{1}$, Ali KARTAL ${ }^{2}$ \\ ${ }^{1}$ Gaziosmanpaşa Üniversitesi, Mühendislik ve Doğa Bilimleri Fakültesi, Mekatronik Müh. Böl., 60250 TOKAT \\ ${ }^{2}$ Akyurt Nevzat Hüseyin Tiryaki Mesleki ve Teknik Anadolu Lisesi, ANKARA \\ ahmet.fenercioglu@gop.edu.tr, alikartal5800@hotmail.com,
}

(Geliş/Received: 04.10.2013; Kabul/Accepted: 11.03.2015)

\begin{abstract}
ÖZET
Demir içermeyen değerli metallerin ayrıştıılmasında eddy akımı yöntemi etkin olarak kullanılmaktadır. $\mathrm{Bu}$ yöntemle çalışan makinelere Eddy Akımı Ayrıştırıcısı denilmektedir (EAA). Ayrıştırıcıda yüksek manyetik alanlı mıknatıslardan oluşan bir tambur yüksek hızlarda döndürülür. Böylece tambur; üzerindeki taşıyıcı banttan geçen metalde bir Eddy akımı oluşturur. Bu akım nedeniyle malzemede oluşan manyetik alan ile tambur alanı etkileşerek bir kuvvet meydana gelir. Bu kuvvet akan atık içerisinden malzemenin ayrışmasıın sağlar. Malzemenin öz kütlesi, biçimi, boyutu, öz direnci, tamburun manyetik alan şiddeti, hızı ve kutup sayısı ayrıştırma kuvvetini belirler. Bu makalede Eddy akımıyla ayrıştırmanın temelini oluşturan yasalara, sistemin teorisine, tamburun yapısına yer verilmiştir. Deneysel kuvvet ölçümleri ile ayrıştırıcının performansının belirlenmesine çalışılmıştır. Prototip EAA tamburu 900 ve $2400 \mathrm{~d} / \mathrm{d}$ arasında belirli hızlarda döndürülerek 50x40, 50x30 ve 50x20 mm boyutlarındaki $1,5 \mathrm{~mm}$ kalınlığında alüminyum, bakır ve pirinç test malzemelerinde oluşan kuvvetler ölçülmüştür. Kuvvet olarak en iyi sonuç 2400 d/d hızda $50 x 40 \mathrm{~mm}$ boyutlarında alüminyum malzemede elde edilmiş̧ir. Elektriksel iletkenliğin yoğunluğa oranı en yüksek olan malzeme alüminyum olduğu için alüminyum ayrıştırmadaki verim daha yüksektir. Ayrıca verim deneylerinde $5-10 \mathrm{~mm}$ boyutlarında alüminyum ve bakır parçacıkların plastikle birlikte içerisinde bulunduğu $2 \mathrm{~kg}$ ' lık atık ayrıştırma işleminde 1500 $\mathrm{d} / \mathrm{d}$ hızın üzerinde $\% 95$ 'in üzerinde bir ayrıştırma başarısı elde edilmiştir.
\end{abstract}

Anahtar Kelimeler: Demirsiz metal ayrıştırıcı, eddy akımlı ayrıştııııı, değerli metallerin geri dönüşümü, manyetik olmayan iletken malzemelerin ayrıştırılması

\section{DETERMINATION OF RECYCLING PERFORMANCE OF SOME NON-FERROUS METALS VIA PROTOTYPE EDDY CURRENT SEPARATOR}

\begin{abstract}
Eddy current method has been used effectively on to separating valuable non-ferrous metals. It called eddy current separator (ECS) due to operates this method. Magnetic drum consisting high field magnets is rotated at high speeds. Thus, drum induces eddy current in the metal while it is passing over the carrier band of ECS. A force occurs due to the effects of this magnetic field and drum field. The force separates non-ferrous metals from the waste. Density, form, size, resistivity, of the materials, magnetic field intensity, speed, pole number of the drum determine separation force. This paper consist of fundamentals rules, theory of ECS system, drum structure. Performance determination was studied with experimental measurements on the prototype ECS. When the magnetic drum of prototype is rotated between 900 and $2400 \mathrm{rpm}$, separation forces are measured on the test

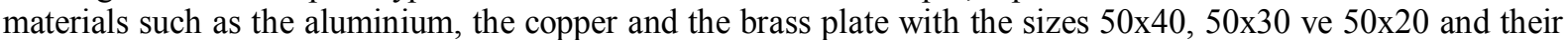
thicknesses are $1.5 \mathrm{~mm}$ respectively. The best force results are achieved with the materials $50 \times 40 \mathrm{~mm}$ at the speed of $2400 \mathrm{rpm}$. Separation efficiency is better on the aluminium material because aluminium has higher rate of electrical conductivity per density. It has been also achieved efficiency over $\% 95$ with the experiments of separation process with $2 \mathrm{~kg}$ waste which is included 5-10 $\mathrm{mm}$ copper, aluminium particles together plastic at higher than $1500 \mathrm{rpm}$ speed.
\end{abstract}

Keywords: Non-ferrous metal separator, eddy current separator, valuable metals recycling, separation of conductive materials 


\section{GIRISŞ (INTRODUCTION)}

Eddy akımı yöntemi, geri dönüşüm teknolojileri alanında, demir içermeyen bakır, alüminyum, altın, gümüş, pirinç gibi değerli metallerin ayrıştırılmasında kullanılmaktadır. Bu yöntem ayrıștırıcı olarak ilk kez Eriez Magnetic firması tarafindan 1969 yılında manyetik olmayan iletken malzemeleri ayrıştırmak için tasarlanmış ve patent alınmıştır. İki tip olarak geliştirilen bu ayrıştırıcının birinci tipinde, malzemede darbeli elektromanyetik alan ile diğer tipinde ise sabit mıknatıslardan oluşan yüksek hızda dönen rotor ile eddy akımı oluşturarak ayrıştırma yapılmıştır [1]. Günümüzde geri dönüşümün önem kazanması, geri dönüşüm teknolojileri alanında yapılacak çalışmalara değer katmaktadır. Özellikle ekonomik değeri yüksek değerli metallerin geri kazanılması ülke ekonomilerine önemli katkılar sağlamaktadır. Son on y1l içerisinde bu konuda uluslararası düzeyde yapılan çalışmalar sinırlıdır, ülkemize ise oldukça az sayıda çalışmaya rastlanmıştır. Bunlardan bazıları özet olarak aşağıda verilmiştir.

Lungu ve Rem [2] $5 \mathrm{~mm}$ den daha küçük metal parçacıklar içeren elektroteknik atıkların ayrıştırılması için yeni tip ve tek-disk olarak adlandırılan bir EAA öngörmüşlerdir. Bu tasarımda yatay pozisyonlu döner tip bir manyetik disk ile küçük parçacıkların ayrıştırılması için deneyler yapılmıştır. Deneyler bakır-kurşun ve bakır-alüminyum karışımlar ile yapılarak sistemin performansı test edilmiștir. Fenercioğlu ve Kurt'un yaptığı çalışmada [3] ayrıştırıcıda, yüksek hızlarda döndürülen sabit miknatıslardan oluşan bir rotor ile malzemede eddy akımı oluşturulduğu ve bu akıma maruz kalan demirsiz metallerde onların öz kütle ve öz dirençlerine göre farklı eddy akımları ve kuvvetler oluştuğu ifade edilmiştir. Bu şekilde alüminyumun geri kazanımı durumunda ortaya çıkan hammaddenin ekonomik değeri ve enerji verimliliği üzerine etkileri incelenmiştir. Zhang ve ark. [4] yaptıkları çalıșmalarında; yeni geliștirilen iki tamburlu EAA'yı ECSIM programı ile simüle etmişlerdir. Simülasyon çalışmalarında parçacıkların yatay olarak yer değiştirmesi ölçülmüştür. İki tamburlu EAA'nın küçük parçacıkları ayrıştırmada avantajlı olduğu ifade edilmiştir. Zhang ve Ark.'nın [5] yaptığı çalışmada malzemede oluşan manyetik itme kuvveti modellenmiștir. Bir EAA için ayrıştırmada başlıca kriter malzemenin yoğunluğunun $(\rho)$, elektriksel iletkenliğe $(\sigma)$ oranı $(\sigma / \rho)$ olduğunu belirtilmiştir. Burada yoğunluk başına iletkenliği daha yüksek olan malzemeler daha kolay bir şekilde ayrıştırılmaktadır. Böylece küçük parçacıkların ayrıştırılma oranının yüksek olduğu görülmektedir.

Wang ve ark. [6] tarafindan yapılan çalışmada, malzeme besleme, konveyör bandı ve tambur hızının ayarlanması sonucunda, ayrıştırma veriminin arttı̆̆ belirtilmektedir. Yapılan deneylerde 2-5 $\mathrm{mm}$ boyutunda ve çeşitli ağırlıklardaki alüminyum ve plastik karışımı içerisinden malzeme ayrıştırılması sırasında tamburun hızı ve konveyör banttın dönüş hızı değiştirilerek deneyler yapılmıştır. Yapılan çalışma sonucunda miknatıslı rotorun $25 \mathrm{~Hz}$ 'de, konveyör banttın ise $8 \mathrm{~Hz}$ 'de döndürüldüğünde verimin \%95'in üzerinde olduğu sonucuna varılmıştır [6]. Hacıfazlıoğlu [7] yaptığı çalışmada ise eddy akımlı ayrıştırıcılar sayesinde, alüminyum gibi demir içermeyen ve yeni geliştirilen manyetik sıvılarla platin grubu metallerin etkili bir şekilde zenginleştirildiğini tespit etmiştir.

\section{MATERYAL YÖNTEM (MATERIAL METHODS)}

\subsection{Eddy Akımı Ayrıştırıcısının Teorisi (Theory of Eddy Current Separator)}

Demir içermeyen değerli iletken malzemelerin ayrıştırılması için, eddy akımı etkin bir yöntemdir. Eddy akımı prensibi; bir iletken malzeme değişken bir manyetik alan içerisine yerleştirildiğinde manyetik akı tarafindan kesilerek Faraday kanununa göre malzemede bir elektrik yükü indüklenir. Kapalı devre olan malzemede Eddy akımı olarak adlandırılan girdap şeklinde akımlar geçer. Bu akımların etkisi ile malzemede Ampere kanununa göre manyetik alan oluşmaktadır. Bu alan mıknatıs bloklarından oluşan rotorun manyetik alanından etkilenir. Her iki alanın etkisi ile Biot-Savart yasasına göre malzemede kuvvet oluşur. $\mathrm{Bu}$ itme kuvveti ile malzeme ürün akışından dışarıya atılır. Bu durumu açıklayan prensip şeması Şekil 1'de verilmektedir. Eddy akımının genliğini, frekansını ve firlatma kuvvetinin büyüklüğünü belirleyen parametreler malzemenin cinsi, öz kütlesi, özdirenci, biçimi, boyutları, tambur ile malzeme arasındaki hav aralığı, rotorun hızı ve kutup sayısıdır.

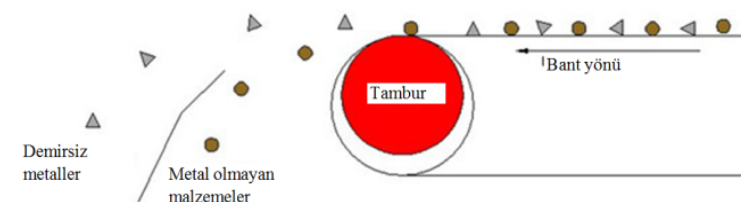

Şekil 1. EAA prensip şeması (Principial scheme of ECS)

Faraday indüksiyon yasasına göre değişken manyetik alana maruz kalan parçacıkta indüklenen akım Eş.1.'de verilmiştir. Burada manyetik akının zamana göre değişim hızı emk'nın ve eddy akımının büyüklüğünü belirlemektedir [8-10].

$\vec{\nabla} x \vec{J}=-\sigma_{p} \frac{\partial \vec{B}}{\partial t}$

Burada $J$ akım yoğunluğu ve $\sigma_{p}$ parçacığın öz iletkenliği, $B$ manyetik akı yoğunluğu ve $t$ zamandır. İndüksiyon akımının yönü Lenz kanunu ile belirlenir. $\mathrm{Bu}$ kanununa göre; indüksiyon akımının yönü kendisini meydana getiren alana zıttır. $\mathrm{Bu}$ karşıt manyetik alanlar, iletkenin bir doğrusal yüzey elemanı 
$(d s)$ üzerinde Eş.2 ile verilen itici bir Lorentz kuvveti üretir [8].

$\vec{F}_{L}=\operatorname{Id} \vec{S} \times \vec{B}$

Burada $I$ iletkenden geçen akımdır. Bu kuvvet parçacığın hareketini sağlar ve yolundan saptırır. Malzemede eddy akımı ile ayrıştırmayı sağlayan kuvvet Şekil 2'de görülen döner tamburlu tip EAA üzerinde gösterilmektedir.
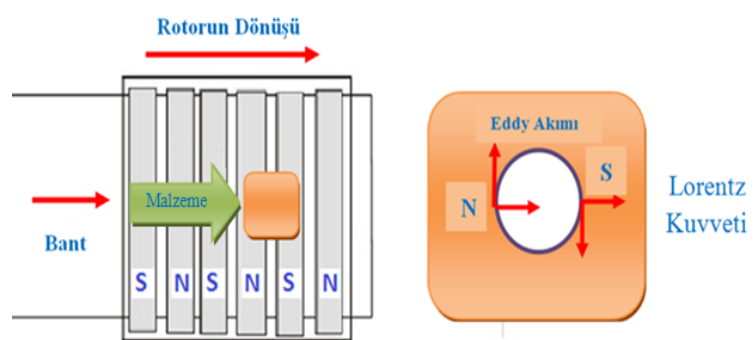

Şekil 2. Döner tamburlu eddy-akım ayrıştırıcısının üsten görünüşü (Top view of the rotary drum eddy current separator)

Eddy akımı nedeniyle parçacıklara etki eden kuvveti hesaplamak için Rem ve ark. [7] tarafindan geliştirilen dipol modeli ve harici manyetik alanlar sonucu oluşan Lorentz kuvveti Eşitlik 3'de ifade edilmektedir [8].

$F_{L p}=\mu_{M} \nabla B$

Burada $F_{L p}$ Lorentz kuvveti (N), $\mu_{M}$ manyetik momenti (Nm) ve $B$ harici manyetik akı yoğunluğunu (T) olarak ifade etmektedir. Parçacıkta oluşan moment ise $\mu_{M}=M_{p} V_{p}$ ile bulunmaktadır [8]. Burada $M_{p}$ parçacığın mıknatıslanması, $V_{p}$ ise $\mathrm{m} / \mathrm{s}$ olarak hızıdır. Eşitlik 2'de olduğu gibi verilen ve bir parçacığa etki eden kuvveti belirlemek için, manyetik sistem tarafindan üretilen manyetik alan hesaplanmaktadır. Tambur eksenine göre silindirik bir koordinat sistemi $(r, \phi, z)$ içerisindeki manyetik indüksiyon bileşenleri Eş.4 ve Eş.5 ile elde edilmektedir $[8,9]$.

$$
\begin{aligned}
& B_{r}={ }_{n=0}^{\infty} b_{n}\left(\frac{r}{R_{\text {drum }}}\right)^{-(2 n+1) k-1} \sin [(2 n+1) k(\varnothing- \\
& \left.\left.\omega_{\text {drum }} t\right)\right]
\end{aligned}
$$

$B_{\emptyset}=\underset{n=0}{\infty}-b_{n}\left(\frac{r}{R_{\text {drum }}}\right)^{-(2 n+1) k-1} \cos [(2 n+1) k(\varnothing-$ $\left.\left.\omega_{\text {drum }} t\right)\right]$

Burada, $b_{n}$ Forier katsayısı, $R_{\text {drum }}$ tambur yarıçapı, $k$ tamburdaki mıknatıs çifti sayısı ve $\omega_{\text {drum }}$ tamburun açısal hızını ifade etmektedir. Fourier katsayısı, parçacığın, manyetik kutup yüzeyinden uzaklığının bir fonksiyonu olarak manyetik alan şiddeti ile belirlenmektedir [8]. Parçacık üzerine etki eden teğet $F_{L p t}$ ve radyal $F_{L p r}$ kuvvetleri, Eş. 4 ve Eş. 5 temel alınarak Eş. 6 ve Eş.7 ile formüle edilmiştir [8-10].

$$
\begin{aligned}
& F_{L p t}=\frac{2 \pi s V_{p}}{\mu_{0} w} \frac{\left(k \omega_{\text {drum }}+\Omega\right) \tau}{1+\left(k \omega_{\text {drum }}+\Omega\right)^{2} \tau^{2}} B^{2} \\
& F_{L p r}=\frac{2 \pi s V_{p}}{\mu_{0} w} \frac{\left(k \omega_{\text {drum }}+\Omega\right)^{2} \tau^{2}}{1+\left(k \omega_{\text {drum }}+\Omega\right)^{2} \tau^{2}} B^{2}
\end{aligned}
$$

Burada, $w$ mıknatısların bir çiftinin genişliğini, $s$ ayrıştırılacak parçacığın şekil faktörünü ve $\Omega$ ise dönen parçacı̆̆ın açısal hızıdır. Tanecik içindeki manyetik alanın bozulmasına neden olan karakteristik zaman $\tau$ dir ve Eşitlik 8'de olduğu gibi hesaplanmaktadır $[8,11]$.

$\tau=\mu_{0} \sigma_{p} s b^{2}$

Burada $b$ parçacığın yarıçapıdır. Parçacıktaki moment yöntemi ile Eş.9 kullanılarak bulunmaktadır [8,11].

$T=\frac{s V_{p}}{\mu_{0}} \frac{\left(k \omega_{\text {drum }}+\Omega\right) \tau}{1+\left(k \omega_{\text {drum }}+\Omega\right)^{2} \tau^{2}} B^{2}$

Eddy-akım kuvvetleri ve oluşan tork, manyetik alanın karesine bağlı olduğu Eş. 9'da olduğu gibi görülebilmektedir. Seramik ferrit doğal mıknatıslar yerine nadir toprak elementi mıknatısların (Neodyum) kullanılması ile ayrıştırma gücünde belirgin bir artış görülmektedir [8]. Şekil 2'de görülen döner tamburlu eddy akım ayrıştırıcısında, döner mıknatıslı tamburun değişken manyetik alanının yol açtığı itici kuvvet Eş. 10 ve Eş.11 ile daha sade biçimde verilmiştir [6].

$F_{r}=H^{2} f \times \frac{m \sigma}{\rho s}$

$\mathrm{f}=\frac{n p}{2}$

Burada $F_{r}$ itme kuvvetini, $H$ Manyetik alan şiddetini, $f$ manyetik alan frekansını, $n$ mıknatıs tamburun hızını, $p$ manyetik kutup sayısını, $m$ kütleyi, $\sigma$ iletkenlik oranını, $S$ malzemenin şekil faktörünü ve $\rho$ yoğunluğu ifade etmektedir. Farklı malzemeler için, bileşik kuvvet malzeme özellikleri ile ilgilidir ve $\frac{\rho}{\sigma}$ oranı itme kuvvetin boyutunu ve ayrıştırma zorluğunun derecesini belirlemektedir [6].

\subsection{Prototip Eddy Akımı Ayrıştırıcısı (Prototype of Eddy Current Separator)}

Prototip eddy akım ayrıştırıcısı bir yüksek lisans tezi olarak tasarlanmış ve deneysel amaçlı olarak imal edilmiştir. Şekil 3'de görülmektedir. Bant sistemi, mıknatıs tambur, gövde ve kontrol panosundan oluşmaktadır. Bant sistemi ayrıştırılacak malzemeleri $0.2 \mathrm{~m} / \mathrm{s}$ sabit hızla taşıyarak mıknatıs tambur üzerinden geçirmektedir. Tambur, bant ile arasında 1 $\mathrm{mm}$ hava aralığı olacak şekilde makineye yerleş̧irilmiş̧ir. Banda temas etmeden uç kısımda yüksek hızla dönmekte olup demirsiz metaller üzerinde eddy akımının ve kuvvetin oluşmasını 
sağlar. Bu nedenle ayrıştırıcısının en önemli parçası miknatıslı tamburdur [11].

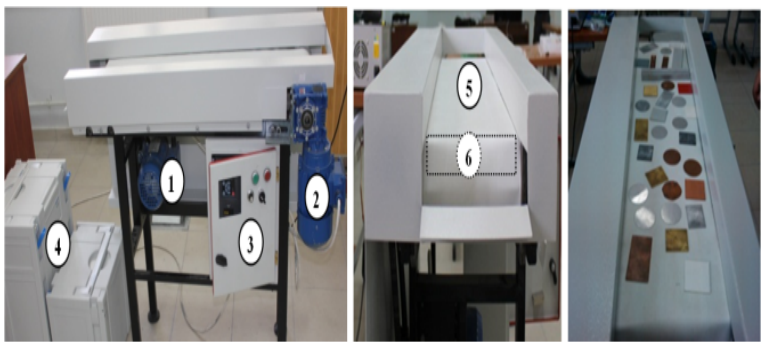

Şekil 3. Prototip Eddy Akımı Ayrıştırıcısı (Prototype of Eddy Current Separator)

1. Tambur motoru 2. Bant motoru 3. Kontrol panosu 4. Ayrıştırılmış ürün kutuları 5. Konveyör bant 6 . Miknatıs tambur

Eddy akımının genliğinin yüksek olması $d \phi / d t$ 'den dolayı akının frekansına bağlıdır. Bu nedenle tambur 24 kutuplu olarak tasarlanmıştır. Bu durumda tambur dakikada $1500 \mathrm{~d} / \mathrm{d}$ olarak döndürüldüğünde malzemede oluşan eddy akımının frekansı $600 \mathrm{~Hz}$ olmaktadır. N52 sınıf neodyum çubuk miknatıs kullanılmıştır. Tamburun yapısı Şekil 4'de gösterilmiştir [11].

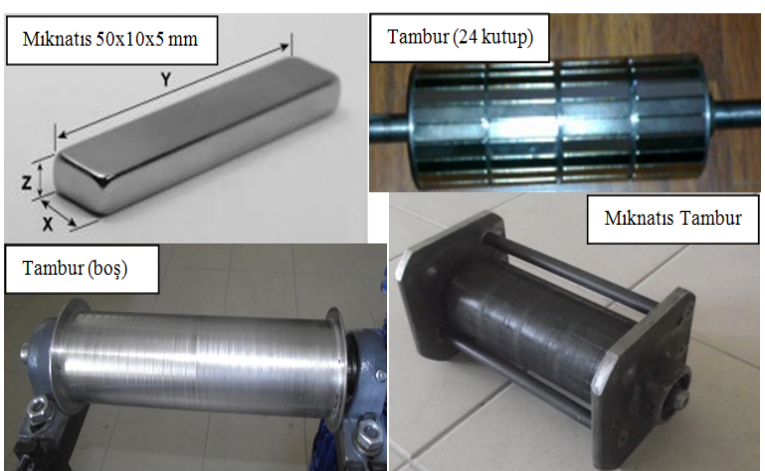

Şekil 4. Mıknatıslı tamburun yapısı (Structure of magnetic drum)

Eddy akımı ayrıştırıcısının oluşturduğu itme kuvveti ve malzemenin ayrıştırma verimi gibi bulgulara ulaşmak için deneysel çalışmalar yapılmıştır. Bu amaçla $50 \times 40 \mathrm{~mm}, 50 \times 30 \mathrm{~mm}$ ve $50 \times 20 \mathrm{~mm}$ boyutlarında 1,5 mm kalınlığında, birbirleri ile eşit hacimlerde alüminyum, bakır ve pirinçten yapılmış test malzemeleri kullanılmıştır.

Malzeme bandın hareketi ile tamburun üzerinden geçerken hava aralığının en dar olduğu bölgede enine olarak manyetik alana maruz kalır. $\mathrm{Bu}$ nedenle malzemenin eni firlatma kuvvetinde etkili olduğu için 20, 30 ve $40 \mathrm{~mm}$ olarak değişken alınmıştır. Boyu ise sabit olarak $50 \mathrm{~mm}$ 'dir. Test malzemeleri Şekil 5'de ağırlıkları ise Tablo 1'de verilmektedir.
Tablo 1.Test malzemelerinin ebatları ve ağırlıkları (Dimensions and weight of test metarials)

\begin{tabular}{|c|c|c|c|}
\hline $\begin{array}{c}\text { Malzeme } \\
\text { Ebatları } \\
\text { (mm) }\end{array}$ & \multicolumn{2}{|c|}{ Malzeme Cinsi ve Kütlesi (g) } \\
\cline { 2 - 4 } & Bakır & Alüminyum & Pirinç \\
\hline $50 X 40$ & 26,81 & 7,76 & 25,58 \\
\hline $50 X 30$ & 20,11 & 5,82 & 19,18 \\
\hline $50 \times 20$ & 13,40 & 3,87 & 12,79 \\
\hline
\end{tabular}

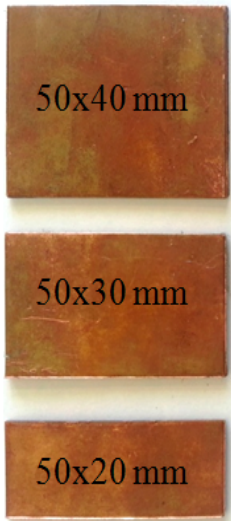

a)

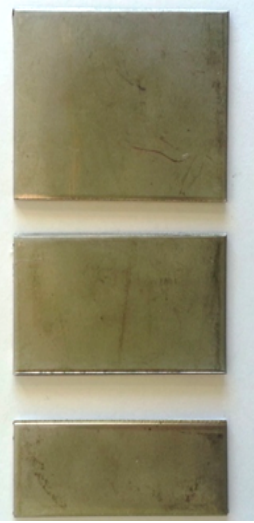

b)

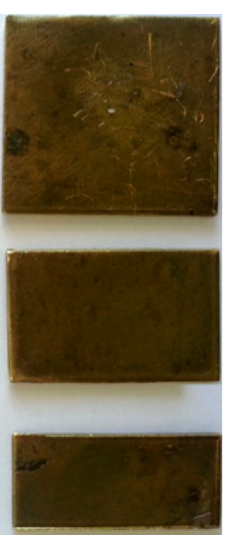

c)
Şekil 5. Test malzemeleri a) bakır b) alüminyum c) pirinç (Test materials a) copper b) aluminium c) brass )

$\mathrm{Bu}$ malzemelerde oluşan itme kuvvetini ölçmek için malzemeler dinamometreye bağlanmıştır. Eddy akım ayrıştırıcısında malzemede oluşan firlatma kuvvetini ölçmek için $10 \mathrm{mg}$ hassasiyete sahip dijital dinamometre kullanılmıştır. Ayrıştırıcının konveyör bandı hareketsiz birakılarak, dinamometre bant üzerine sabitlenmiştir. Sabitlenen dinamometrenin ucuna ayrıştırılacak olan test malzemesi Şekil 6'daki gibi bağlanmıştır [11].

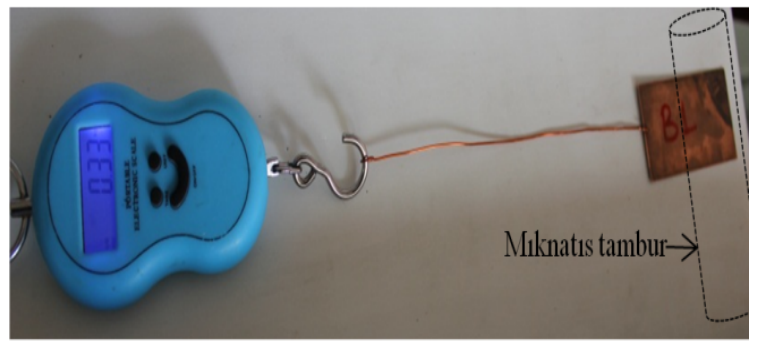

Şekil 6. Dinamometre ile kuvvet ölçümü (Measuring force with dynamometer)

$\mathrm{Bu}$ test malzemeleri, miknatıslı tamburun manyetik alanına sokularak farklı dönme hızlarında malzemede oluşan kuvvetler ölçülmüştür. $\mathrm{Bu}$ ölçme işleminde malzemenin tamburdan firlaması esnasında, malzeme dinamometre tarafından tutulmuş olup firlaması engellenmiştir. Malzemenin maksimum kuvvetle askıda kaldığı bu noktada oluşan firlatma kuvvetleri, tamburun 900,1200,1500,1800, 2100 ve $2400 \mathrm{~d} / \mathrm{d}$ hızlarında çalışırken ölçülmüştür. 
İkinci deney olarak, eddy akımı ayrıştırıcısının verimini hesaplamak için 500 gr'1 plastik olmak üzere, 2000 gr ağırlığında farklı cins ve ebatlarda hazırlanmış manyetik olmayan (demir içermeyen) iletken metaller ve plastik karışımı ayrıştırılmıştır. Motor sürücüsü ile mıknatıslı tambur 900, 1200, $1500,1800,2100$ ve $2400 \mathrm{~d} / \mathrm{d}$ hızlarda döndürülerek ayrıştırma işlemi yapılmıştır.

Her hızda ayrıştırılan malzeme miktarı tartılıp toplam demirsiz metal malzeme miktarına oranlanarak verim hesaplanmıştır.

\section{BULGULAR ve TARTIŞMA (RESULTS and DISCUSSION )}

\subsection{Deneysel Veriler (Experimental Data)}

Eddy akımı ayrıştırıcısı, prototibi üzerinde yapılan birinci deney çalışması sonucunda elde edilen kuvvet ölçümleri her test malzemesi için ayrı ayrı grafikler halinde Şekil 7'de verilmektedir.

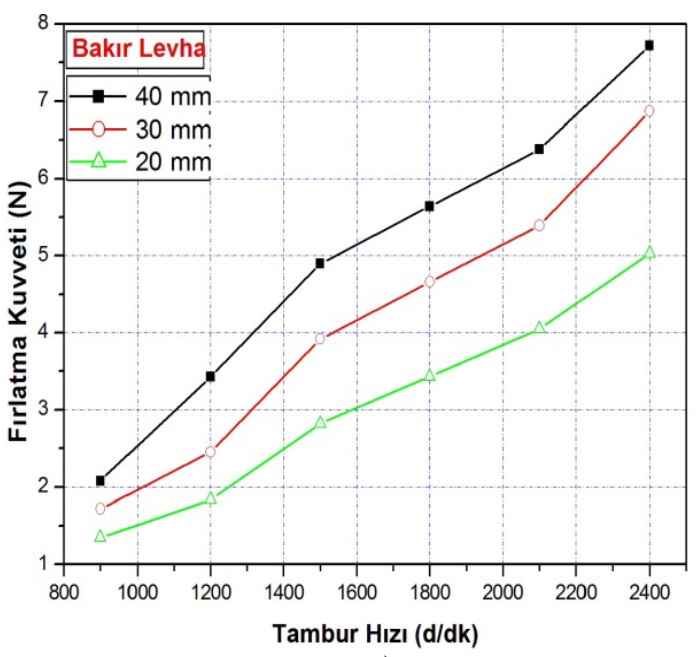

a)

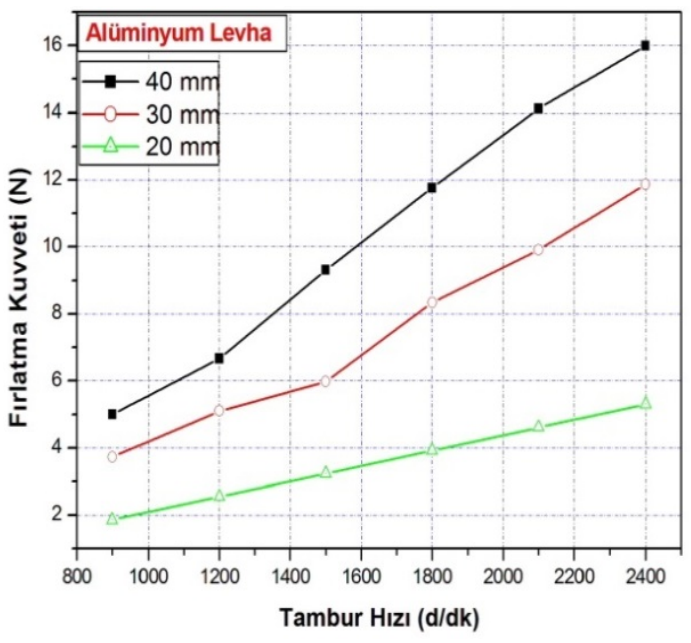

b)

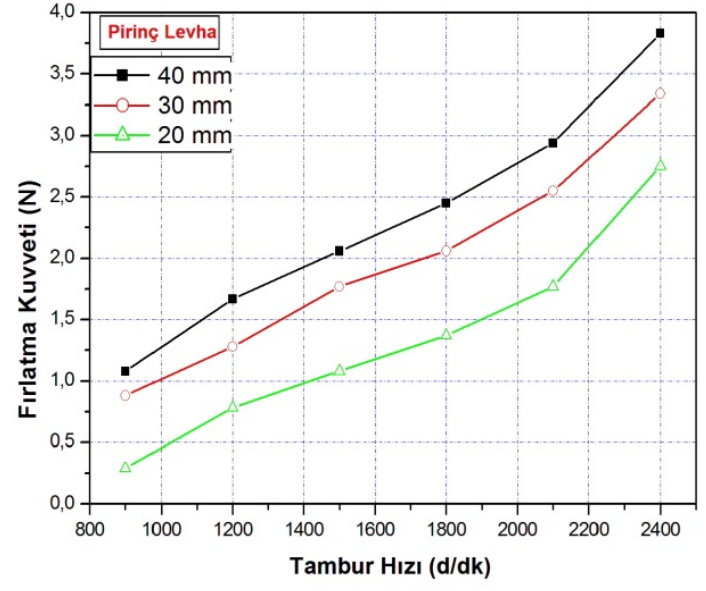

c)

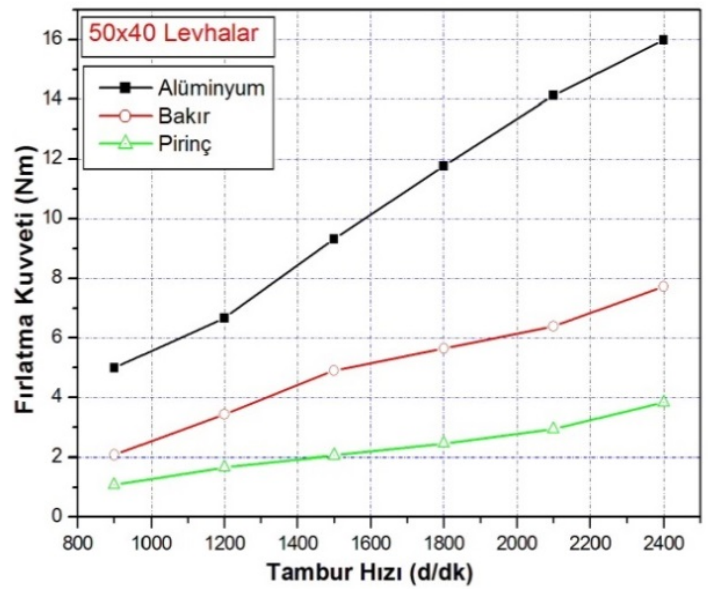

d)

Şekil 7. Fırlatma kuvveti ölçümleri a) Bakır b) Alüminyum c) Pirinç d) 50x40 mm (Measurements of throwing force a) Copper b) Aluminium c) Brass d) $50 \times 40 \mathrm{~mm}$ )

Bakır, alüminyum ve pirinç test malzemeleri kendi içerisinde boyutlar dikkate alınarak tambur hızına göre firlatma kuvveti grafikleri çizilmiştir. Şekil 7 d)'de ise aynı boyuttaki (50x40) farklı malzemelerin tambur hızına göre firlatma kuvveti grafikleri çizilerek birbiri ile karşılaştırılmıştır.

Deney sonuçlarına göre aynı ebatlardaki farklı malzemelerde aynı hız değeri için oluşan kuvvetler birbirinden farklıdır. Malzeme ebatları ve mıknatıslı tamburun dönme hızı, aynı olduğu halde oluşan kuvvetlerin farklı olmasının nedenleri malzeme cinsinin, boyutların, elektriksel iletkenliğin ve yoğunluğunun farklı olmasından kaynaklanmaktadır. Zhang ve ark. [5] bir eddy akımı ayrıştırıcısı için başlıca kriter olarak yoğunluğun, elektriksel iletkenliğe oranı $\sigma / \rho$ olduğunu belirtmektedir. Deneyde kullanılan test malzemeleri bu açıdan incelendiğinde $\sigma / \rho$ oranı en yüksek olan alüminyumun ayrıştırma başarısının daha yüksek olduğu Tablo 2'den de anlaşılmaktadır. Böylece elektriksel iletkenliği yüksek ve öz kütlesi düşük olan malzemeler daha kolay ayrıştırılabilmektedir. Ayrıca malzeme boyutları büyüdükçe indüklenen eddy akımı 
ve manyetik alanı oluşturan yüzey büyüdüğü için ayrıştırma kuvvetinin arttığ 1 Şekil 7'deki grafiklerden görülmektedir [5].

Tablo 2. Test malzemelerindeki $\sigma / \rho$ oranlar1 $(\sigma / \rho$ rates of test materials)

\begin{tabular}{|l|c|c|c|}
\hline \multicolumn{1}{|c|}{ Malzeme } & $\begin{array}{c}\text { İletkenlik }(\sigma) \\
(\text { siemens })\end{array}$ & $\begin{array}{c}\text { Öz kütle } \\
(\rho)\left(\mathrm{g} / \mathrm{cm}^{3}\right)\end{array}$ & $\sigma / \rho$ \\
\hline Alüminyum & 35 & 2,59 & 13,51 \\
\hline Bakır & 58 & 8,94 & 6,48 \\
\hline Pirinç & 17 & 8,53 & 1,99 \\
\hline
\end{tabular}

Deneyde tamburun hızı artıkça, ölçülen kuvvetin de arttığı Şekil 7'de görülmektedir. Örneğin 50x30 mm alüminyum malzeme ayrıştırılırken mıknatıslı tambur $900 \mathrm{~d} / \mathrm{d}$ ile döndürüldüğünde ölçülen kuvvet 3,73 N iken, $2400 \mathrm{~d} / \mathrm{d}$ hızda ölçülen kuvvet 11,87 $\mathrm{N}$ dur. Mıknatıslı tamburun hızı artıkça değişken manyetik alanın frekansı arttığı için Faraday yasasına göre oluşan eddy akımının genliği ve dolayısıyla etkiyen kuvvet de artmaktadır.

İkinci deneyde Eddy akımı ayrıştırıcısının verimine yönelik testler yapılmıştır. $\mathrm{Bu}$ deneyde karışım halinde $2 \mathrm{~kg}$ ağırlığında, 5-10 mm'den 50-100 mm'ye kadar farklı boyut ve biçimlerdeki alüminyum, bakır ve pirinç malzemeleri ayrıştırılmıştır. Tablo 3'de Eddy akımı ayrıştırıcısı prototipinin farklı çalışma hızlarında elde edilen verimi gösterilmektedir. $\mathrm{Bu}$ uygulamada mıknatıslı tamburun dönüş hızının 1200 $\mathrm{d} / \mathrm{dk}$ ve üzerinde olduğunda, ayrıştırıcının $\% 90$ üzerinde bir verimle çalıştığ 1 görülmektedir [11].

Tablo 3. Eddy akımı ayrıştırıcısının verimi (Efficiency of Eddy current separator)

\begin{tabular}{|c|c|c|c|c|}
\hline & & & \\
\hline & & & \\
\hline 900 & $1300 \mathrm{~g}$ & $200 \mathrm{~g}$ & $1800 \mathrm{~g}$ & $\% 90$ \\
\hline 1200 & $1330 \mathrm{~g}$ & $170 \mathrm{~g}$ & $1830 \mathrm{~g}$ & $\% 91,5$ \\
\hline 1500 & $1380 \mathrm{~g}$ & $120 \mathrm{~g}$ & $1880 \mathrm{~g}$ & $\% 94$ \\
\hline 1800 & $1420 \mathrm{~g}$ & $80 \mathrm{~g}$ & $1920 \mathrm{~g}$ & $\% 96$ \\
\hline 2100 & $1420 \mathrm{~g}$ & $80 \mathrm{~g}$ & $1920 \mathrm{~g}$ & $\% 96$ \\
\hline 2400 & $1440 \mathrm{~g}$ & $60 \mathrm{~g}$ & $1940 \mathrm{~g}$ & $\% 97$ \\
\hline
\end{tabular}

Burada düşük hızlarda ayrıştırılamayan ve kayıp metal olarak nitelendirilen 5-10 $\mathrm{mm}$ boyutlarında küçük bakır ve alüminyum parçacıklardır. Küçük boyutlarda değerli metallerin en verimli şekilde ayrıştırılması için, mıknatıslı tamburun dönüş hızının $1500 \mathrm{~d} / \mathrm{d}$ ve üzerinde olması gerektiği görülmüştür. Daha düşük ebattaki parçacıkları ayrıştırılması için bandın taşıdığı malzeme miktarı, bant dönüş hızı ve mıknatıslı tamburun dönüş hızının ayarlanması gerekmektedir. Yapılan prototipte, konveyör bant hızı
$0.2 \mathrm{~m} / \mathrm{s}$ olarak redüktör ile sabitlenmiştir. Ayrıştırıcı bu şartlarda yüksek verimde ayrıştırma yapabildiği için bu hız yeterli kabul edilmiştir. Ayrıştırıcının mekanik sınırlarından dolayı $2400 \mathrm{~d} / \mathrm{d}$ den daha yüksek tambur hızlarında deney yapılamamıştır. Granül halindeki malzemelerin ayrıştırılması daha yüksek hızlarda mümkündür. Küçük boyuttaki parçacıkların ayrıştırılabilmesi için ayrı bir deney yapılmıştır. Bu deney ile $1500 \mathrm{~d} / \mathrm{d}$ ' dan daha yüksek hızlarda 5-10 $\mathrm{mm}$ boyutlarında alüminyum ve bakırdan oluşan malzemelerin ayrıştırılabilmesi sağlanmıştır. Ayrıştırılmış küçük malzemeler Şekil 8'de görülmektedir [11].

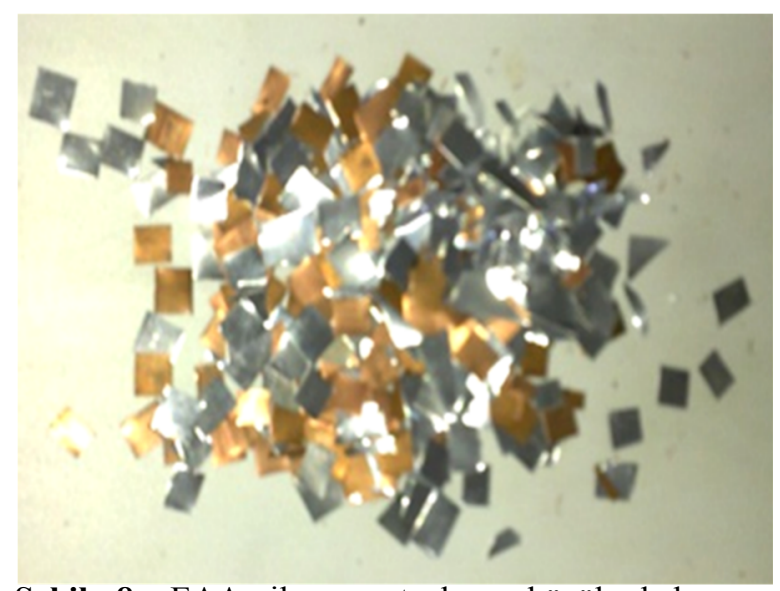

Şekil 8. EAA ile ayrıştırılmış küçük bakır ve alüminyum parçacıklar (Small copper and aluminium particles which are separated by ECS)

\section{SONUÇ (CONCLUSION)}

Atıklar içerisinden demir içermeyen (ferromanyetik olmayan) değerli metalleri ayrıştırabilen bir prototip EAA üzerinde laboratuvar ortaminda deneyler yapılarak, ayrıştırma sırasında malzeme üzerinde oluşan ayrıştırma kuvveti, ve ayrıştırma verimi incelenerek küçük parçacıkların ayrıştırılması test edilmiştir. Bunun için belirli ebatlarda hazırlanmış bakır, alüminyum ve pirinç gibi test malzemeleri üzerinde oluşan firlatma kuvvetleri bir deney düzeneği içerisinde dinamometre ile ölçülmüştür. Bu ölçümler sonucunda malzemeden ve ayrıştırıcıdan kaynaklanan etkenlerin ayrıştırma kuvvetini belirleyici olduğu deneylerle doğrulanmıştır. Malzemenin cinsi, biçimi, elektriksel iletkenliği, öz kütlesi, boyutları malzemeden kaynaklanan etkilerdir. Yoğunluk başına iletkenliği daha yüksek olan malzemelerin daha kolay bir şekilde ayrıştırıldığı test edilmiştir. Tambur ve malzeme arasındaki hava aralığı, mıknatıslı tamburun hızı, mıknatısların manyetik alan şiddeti ve kutup sayısı ayrıştırıcının tasarımından kaynaklanan ve kuvveti etkileyen faktörlerdir. Tamburun hızı ve kutup sayısı Faraday yasasındaki d $\phi / d t$ 'den dolayı malzemede oluşan eddy akımının genliğini artırmaktadır. Böylece Ampere yasasına göre bu akımdan dolayı oluşan manyetik alanın artışı Biot-Savart kanununa göre malzemede oluşan firlatma kuvvetini artırmaktadır. Deneyler 
sirasinda miknatıslı tamburun hiz1 900-2400 d/d hızları arasında değiştirilerek, ayrıştırılan test malzemeleri üzerindeki kuvvetler ölçülmüştür. Ölçüm sonucunda hız artıkça itme kuvvetinin arttı̆̆ görülmüştür. Böylece tambur hızının Eddy akımının genliğine ve malzemede oluşan kuvvete olan etkisi belirlenmiştir. $50 \times 40,50 \times 30$ ve $50 \times 20 \mathrm{~mm}$ ebatlarındaki bakır, alüminyum ve pirinçten oluşan test malzemeleri ile yapılan deneylerde, manyetik alana maruz kalan malzeme yüzeyi küçüldükçe oluşan kuvvetin azaldığ1 görülmüştür. Malzeme boyutunun küçülmesi ile indüklenen Eddy akımı azalmaktadır. Akımın azalması ile malzemede oluşan manyetik alan da azalarak ayrıştırma kuvvetinin düşmesine neden olmaktadır. Malzemeler küçüldükçe ayrıştırmanın zorlaştığ 1 bu deneylerden anlaşılmaktadır.

Sistemin verimine yönelik yapılan deneylerde, mıknatıslı tamburun dönüş hızının ayrıştırılan malzeme miktarına etkisi olduğu tespit edilmiştir. Prototipin miknatıslı tamburu yaklaşık 900-1200 d/d hızlarında çalıştığında, ayrıştırma verimi \%90 civarında olup 5-10 mm boyutlarında küçük parçacıklar yeterince ayrıştırılamamıştır. Tambur hızı $1500 \mathrm{~d} / \mathrm{d}$ ve üzerindeyken ayrıştırmada elde edilen verim \%94'ün üzerindedir ve küçük parçacıklar büyük ölçüde ayrıştırılabilmiştir. Ayrıca konveyör, bant yüzeyine düzgün dağılmamış yı̆̆ın halinde atık malzeme taşıdığında, ayrıştırma veriminin azaldığ görülmüştür. $\mathrm{Bu}$ nedenle malzemelerin bant üzerine düzgün olarak dağıtılması gerekmektedir. Bunun için uygun bir yükleyici ya da vibratör kullanılması önerilmektedir.

Deneylerde alınan verilere göre yapılan prototip genel olarak 5-10 mm'den büyük ferromanyetik olmayan değerli metalleri, \%90'nın üzerinde bir verimle ayrıştırılabilmektedir. Yapılan eddy akımı ayrıştırıcısı prototipinde, konveyör banttın hızı $0,2 \mathrm{~m} / \mathrm{s}$ olarak sabit tutulmuştur. Bandın hızlı olması durumunda malzeme daha kısa süre içerisinde tamburun alanına maruz kalacağı için ayrıştırılacak değerli metaller üzerinde eddy akımı ve kuvvet oluşumunu olumsuz etkileyecektir. Ancak büyük malzemelerde bant hızının belirli bir değere kadar artması büyük malzemelerin ayrıştırılmasında verime etkisi dikkate değer olmayacaktır. Banttaki hız değişikliği birim zamanda ayrıştırılacak malzeme miktarını etkileyecektir. Öngörülen ayrıştırıcı ile endüstriyel atıkların bol bulunduğu talaşlı üretim yapan imalat sektöründe ve evsel atıkların daha çok bulunduğu belediyelere ait çöplüklerde atık halde bulunan alüminyum, bakır, pirinç gibi değerli metallerin ayrıştırılarak hammadde üretimine geri dönüşümü sağlanabilir. $\mathrm{Bu}$ şekilde geri dönüşümle değerli metallerin geri kazanılması ile hammadde tedariğine, ekonomiye, doğal kaynakların tüketiminin azalmasına, enerji tasarrufuna ve çevreye önemli katkıları olacaktır.

\section{TEŞEKKÜR (ACKNOWLEDGEMENTS)}

$\mathrm{Bu}$ çalışma Gaziosmanpaşa Üniversitesi Bilimsel Araştırma Projeleri Birimi tarafindan 2012/62 nolu proje ile desteklenmiştir.

\section{KAYNAKLAR (REFERENCES)}

1. Dobney, S.J., "Eddy Current Separators", IEE Colloquium on Permanent Magnet Machines and Drives, London, Cilt 9, 1-3, 5 Şubat 1993.

2. Lungu, M., Rem, P., "Eddy-Current Separation of Small Nonferrous Particles By A Single-Disk Separator with Permanent Magnets", IEEE Transactions on Magnetics, Cilt 39, No 4, 2062-2067, 2003.

3. Fenercioğlu, A. ve Kurt, Ü., "Manyetik Olmayan İletken Malzemelerin Ayrıştırılmasında Eddy Akımı Yönteminin Kullanılması ve Alüminyumun Geri Kazanılması Örneği”, UMES 2007, Kocaeli, Cilt 2, 712-715, 20-22 Haziran 2007.

4. Zhang, S., Rem, P.C. ve Forssberg, E., "Particle Trajectory Simulations Of Two-Drum Eddy Current Separators", Resources Conversation \& Recycling, Cilt 26, 71-90, 1999.

5. Zhang, S., Forssberg, E., Arvidson, B., Moss, W., "Separation Mechanisms and Criteria of A Rotating Eddy-Current Separator Operation", Resources Conversation \& Recycling, Cilt 25, 215-232, 1999.

6. Wang, Q., Zhao, Y., Jiao, H., Zhang, H., "Effects of Operation Parameters of Eddy Current Separator on Aluminium Separation", 7th World Congress on Recovery, Recycling and Reintegration, Pekin, Çin, 2005.

7. Hacifazlığlu, H., "Manyetik Ayrımadaki Son Gelişmeler ve Alternatif Manyetik Ayırıcı Tiplerinin Tanıtılması", İstanbul Yer Bilimleri Dergisi, Cilt 24, No 1, 75-93, 2011.

8. Svoboda, J., Magnetic Techniques for the Treatment of Materials, Kluwer Academic Publishers, A.B.D., 2004.

9. Rem, P., Beunder, E.M. ve Akker, A.J., "Simulation of Eddy-current Separators", IEEE Transaction on Magnetics, Cilt 34, No 4, 22802286, 1998.

10. Zhang, S., Rem, P.C. ve Forssberg, E., "The Investigation of Separability of Particles Smaller Than $5 \mathrm{~mm}$ By Eddy-Current Separation Technology, Part I: Rotating Type Eddy-Current Separators". Magnetic and Electrical Separation, Cilt 4, 233-251, 1999.

11. Kartal, A., "Değerli Metallerin Eddy Akımı Yöntemiyle Ayrıştırılması”, Yüksek Lisans Tezi, Gaziosmanpaşa Üniversitesi, Fen Bilimleri Enstitüsü, 2012. 
